\title{
More Passengers and Reduced Costs-The Optimization of the Berlin Public Transport Network
}

\author{
Tom Reinhold, A. T. Kearney GmbH
}

\begin{abstract}
The Berliner Verkehrsbetriebe (BVG) has succeeded in increasing its revenue by more than 22 percent in three years. This was made possible by restructuring the transportation network as part of an integrated marketing strategy. Traffic simulations demonstrated that improving frequency on the main lines could shorten travel times and attract many new customers to public transportation. In addition, lines outside the core network with little utilization were identified where service could be reduced to achieve significant cost savings with only a slight decline in the number of passengers. In 2004, new premium products, the MetroBus and MetroTram, were introduced; in 2006, their services were improved yet further. Today, the MetroBus and MetroTram run on the 26 most important lines (in addition to the subway), 24 hours a day at very short intervals. They are intensively marketed, and customers can understand the Metro network almost as well as they can the subway network. The new MetroBus and MetroTram products have achieved great success, with passenger volume on some lines rising by more than 30 percent. Overall, the BVG has gained more than 21 million new trips per year and reduced its annual operating costs by more than 9.5 million euros.
\end{abstract}




\section{Introduction}

All public transportation companies in Germany depend on various types of subsidies to provide their range of services because ticket fares alone do not cover operational costs. Budget constraints in public funding over the past several years have reduced the level of subsidies for public transportation in Germany, and prompted demands for considerably greater efficiency in public transport operations.

The transportation companies have succeeded in raising efficiency levels over the past several years; they are covering expenses to an increasing degree and thus reducing their need for subsidies. In general, they have achieved these results through cost-saving efforts such as cutting services, streamlining organizational structures, and improving process efficiency. The companies have found it much more difficult, however, to improve results by increasing revenues.

The BVG (Berliner Verkehrsbetriebe) is also currently undergoing a restructuring process. When the BVG (West Berlin) and the BVB (East Berlin) merged in the early 1990s, the company had a combined total of more than 28,000 employees. Only about 11,000 of them remain today. These advances on the cost side, however, have been met with only moderate increases or stagnation in ticket revenue since the late 1990s. In 2002, ticket revenue decreased for the first time. As a consequence, BVG management took a number of steps in early 2003 to increase revenues from ticket sales. These steps focused on integrated marketing with the aim of utilizing all four relevant mechanisms-new services, fare structures, advertising, and sales-and on the customers themselves, namely on what services they need and on how much they are prepared to pay for them.

Based on this approach, BVG management launched the BVG 2005 Plus project in 2003 to optimize services. By December 31, 2004, the greatest change in timetables in the history of the BVG had taken place. In the process, the company also introduced two new products, MetroBus and MetroTram, initially as daytime services and, later, during the night as well.

This project represented another ground-breaking activity for the BVG. For years, services had largely been determined on the basis of optimizing operations. But now, the BVG undertook a comprehensive, corridor-by-corridor analysis of all traffic patterns in the city and of the strengths and weaknesses of the public transportation system. Moreover, customers and media representatives were included in the planning, not only to increase acceptance for the project, but also to incorporate as many ideas and suggestions for improvement as possible. 
Despite the strong wish to orient services toward customers, the project faced the additional challenge of having to cut operations and therefore costs to a signifcant degree at the same time. The ambitious aim of the project, namely to increase the number of customers by 2 percent while simultaneously cutting operations by 3 percent, was frequently described as akin to squaring a circle. The fact that it nevertheless succeeded, and with tight deadlines as well, is due to an extraordinary effort put forth by many BVG employees, especially from the planning offices of the central marketing department, the bus and tram divisions, and public relations, as well as from external engineering offices, consulting firms, and agencies. Not without pride, we note that comparable projects in other German metropolitan centers faced less daunting conditions. Hamburg, for example, was not forced to cut costs on introducing its Metrobuses, and Munich had considerably more time to incorporate input from its residents and district representatives.

The new daytime schedules went into effect in December 2004. In May 2006, the MetroLines, which had operated only during the day until this time, started 24hour-service; these new lines are now available 24 hours a day, 7 days a week. This change was part of a general expansion of nighttime service that also included the metro (underground) system. Berlin thus took another step toward being "open around the clock." Figure 1 presents an overview of the project plan.

In the beginning the planning process was analyzed to determine its strengths and weaknesses, and a target process was developed whose structure and agreedupon milestones were designed to coordinate both the various BVG internal areas (mainly the central marketing department including both service development and marketing communications, the metro, tram, and bus divisions, central controlling, and workers' representatives) and external partners (especially the Berlin State Senate as the authorizing agency, district offices and traffic commissions, the public transport federation, the S-Bahn [commuter rail company], passenger organizations, and the customers themselves). As it turned out, both internal and external resistance to such a process of change cannot be underestimated.

In three further stages of analysis, the BVG studied customer needs, competition between public transportation and individual cars in Berlin, and capacity utilization levels in its transport systems to systematically expand its existing databases, some of which were good, but others of which showed gaps. In planning nighttime services, it used a part-time matrix for the first time to determine demand. 


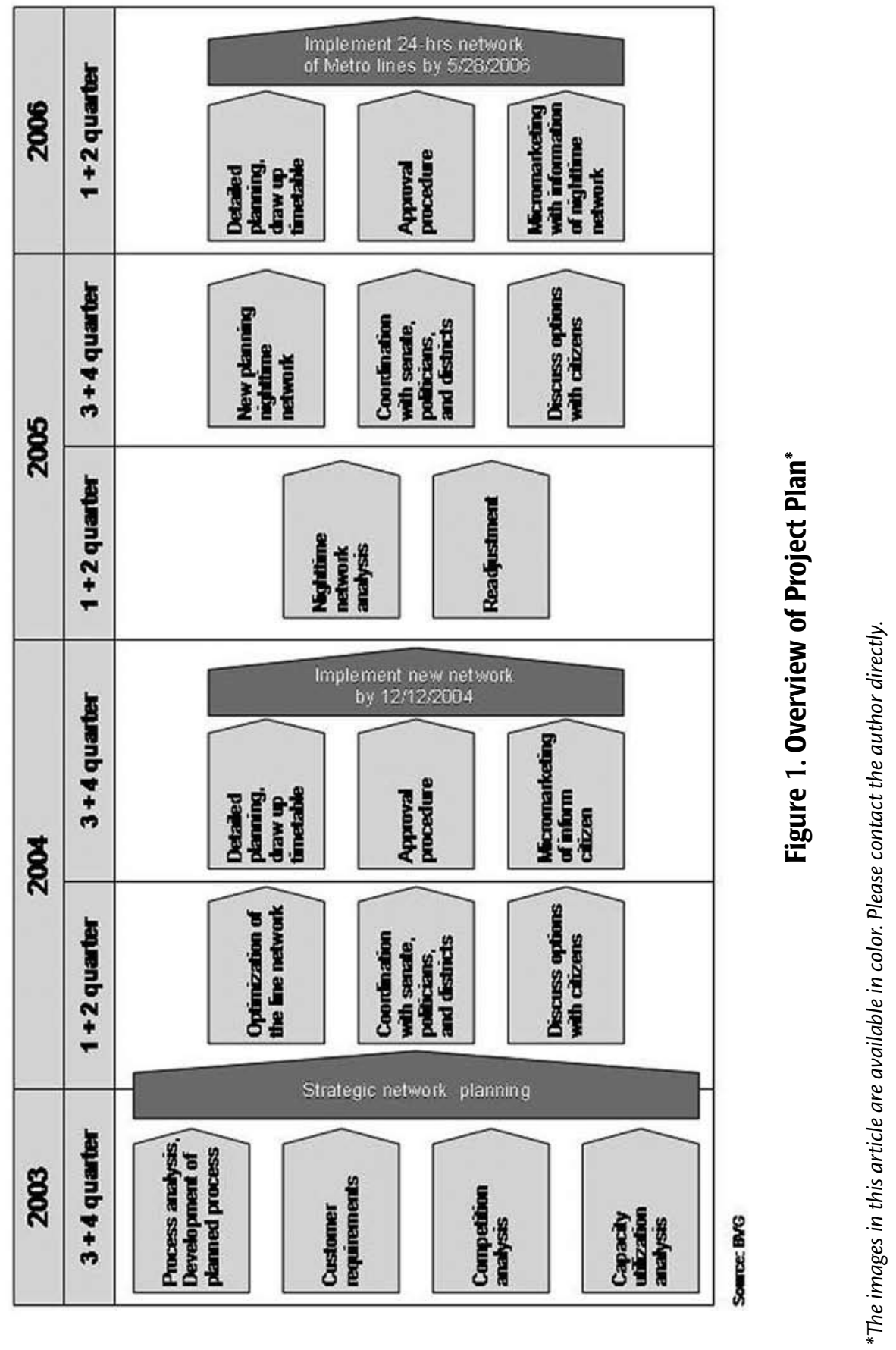




\section{Factors in Selecting Transportation Services}

Innumerable studies have been done on what customers want from public transportation systems. Most of them, however, generate a comprehensive catalog of needs and conclude that customers are dissatisfied with virtually everything or that they see potential for improvement just about everywhere and that regular customers are even more critical than occasional customers. As far as company decisions go, these studies are usually not helpful because they offer no approaches for how best to utilize scarce resources. Instead, priority must be given to projects that improve services in such a way that they actually attract new customers, as opposed to only increasing the satisfaction of customers that the company already has anyway.

On the basis of the studies that it employed with different methodologies, the BVG therefore explicitly sought to identify the crucial commercial factors whose improvement could lead directly to an increase in the number of customers. The studies revealed that 80 percent of respondents desire short travel times, a result that far surpassed all other suggested ways of improving public transportation services in Berlin. The conclusion that travel time is the dominant factor may appear trivial, yet on closer examination it is astonishing how the other factors pale in comparison-including safety and cleanliness, which together accounted for only 12 percent of total responses. Among other things, the fact that these criteria are currently adequately met reflects the BVG's intention not to discourage any customers from public transportation (which is not to deny that some customers would desire further improvements in these areas). The same is true for a virtually nonexistent willingness on the part of Berliners to pay more for a greater level of comfort. Although many customers would surely be pleased about further improvements in comfort, a sufficient level has already been achieved. More advances in comfort would therefore attract hardly any more customers.

The crucial factor of travel time comprises the entire journey from door to door, as compared to the alternative of driving a private car. The major constituent elements in door-to-door public transportation service are the following:

- average speed of public transport vehicles

- intervals between vehicles (i.e., the amount of time spent waiting for the initial vehicle and any subsequent vehicles following transfers)

- number and/or necessity of transfers

- density of stations or stops (i.e., the distance from residence and destination to the nearest station or stop) 
A very detailed study of these elements showed that the majority of respondents placed the highest priority on short intervals between vehicles. If faced with a choice between service running at very short intervals (10 minutes or less) and a somewhat greater distance to the nearest station or stop (10- to 15-minute walk) versus service running at longer intervals (20 minutes) with a station or stop in the immediate vicinity, the overwhelming majority preferred the longer walk. The lines with the highest levels of customer satisfaction are those that run at intervals so short that customers do not even need to look at the timetable.

To attract new customers at the same level of resources, one must also consider cutting service on infrequently-used lines or stops and accepting the resulting slight decline in passenger volume to shorten intervals on well-frequented lines to 10 minutes or less. Customers will also accept up to two transfers if short intervals (or optimized connections) mean that they only have to wait for a short period of time (see Figure 2).

\section{Competitor Analysis}

The high importance that trip duration has on the choice of transportation is clear not only from the study results, but also from considering the actual modal split values on different corridors. A competitor analysis was performed based on traffic simulations that used many counts of adjusted, comprehensive spatial comparisons of travel times for public transportation versus private cars. The spatial units studied represented the traffic cells and fractions of traffic cells for the Berlin metropolitan area. The study was designed to compare the following for different subcells:

- changing levels of demand for transportation in general

- travel times for public transportation versus private cars

- market shares for public transportation

Traffic flows whose results exceeded certain ratios for the above points can be viewed as promising areas for acquiring new customers (i.e., as areas where there is a need for action). With around 1 million possible ratios, the BVG analysis therefore focused on traffic flows that are large (high level of potential traffic consolidation), that currently have a high share of private car traffic, and that show relatively poor travel times for public transportation (see Figure 3 for example). Here, new customers could be induced to make the switch from private cars to public transportation by means of improved service such as new direct connections, acceler- 

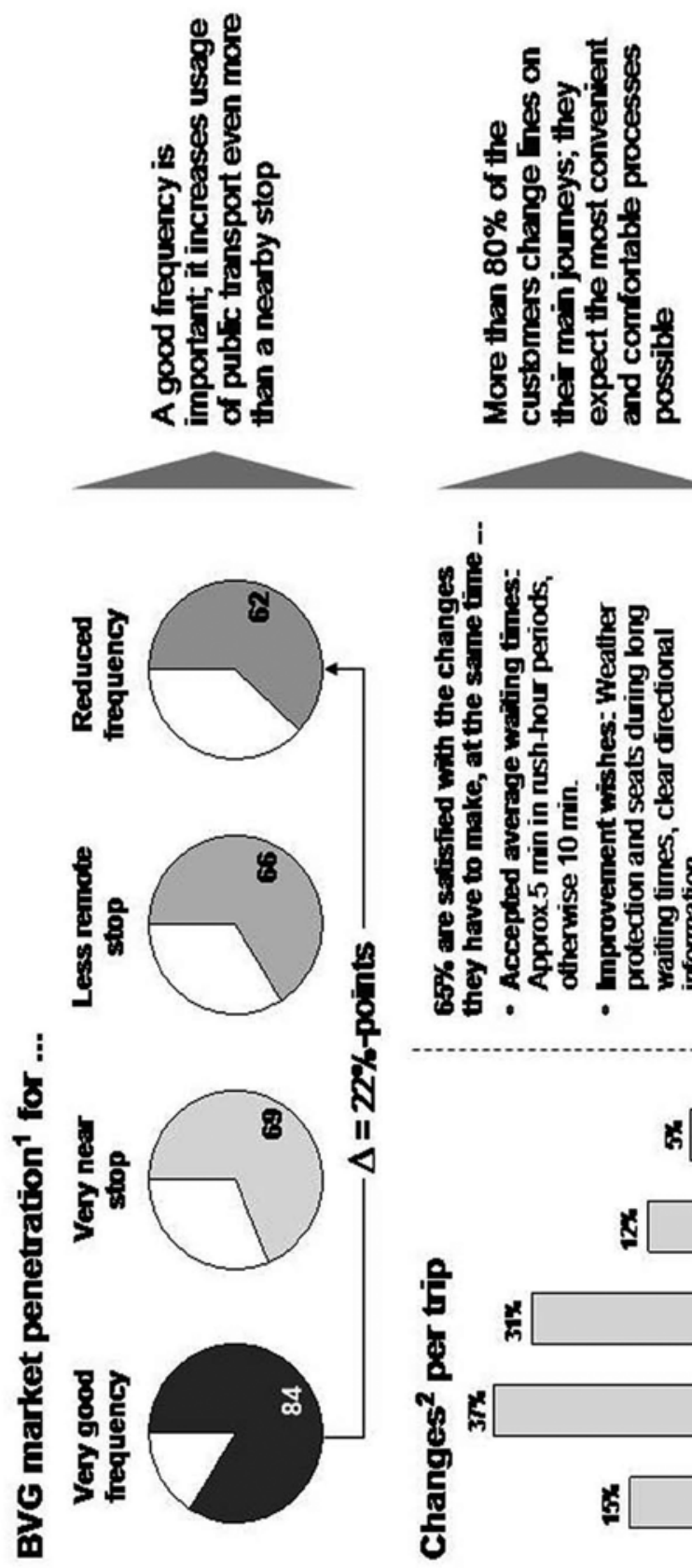

ปั
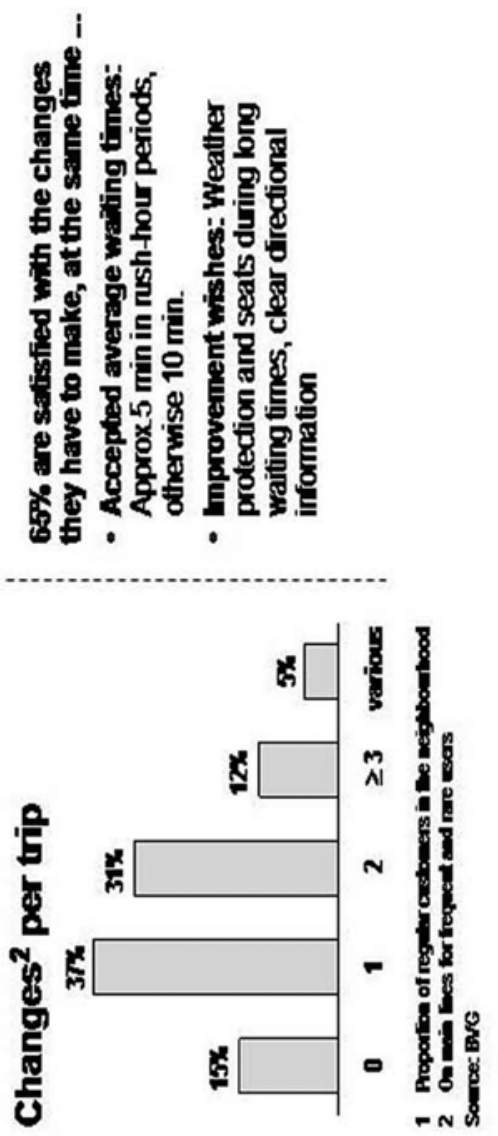

을 
ated transit, or shorter intervals. A relevant number of such ratios were found and used to plan concrete measures (see Figure 4).

Of course, there are many other reasons than relative travel times that influence the modal split, such as sociodemographic structures at the source and destination areas, availability of private cars, and regional parking facilities. By far the clearest correlation, however, is found between the modal split and relative travel times. The following conclusions were reached:

- For door-to-door service, private cars are faster than public transportation on all high-demand corridors.

- Public transportation can achieve very high market shares of more than 80 percent as long as it requires no more than one and a half to two times as much time as private cars.

- Public transportation still retains a relatively high market share of around 30 percent (for "captive" users) even if it offers extremely poor travel times.

\section{Capacity Analysis}

Whereas the "top-down" competitor analysis was designed to yield primarily new customer potential for public transportation, a "bottom-up" capacity analysis was used to determine how well current service meets the demand and what if any potential for savings might be present. Capacity was calculated precisely in the form of seat kilometers divided by passenger kilometers expressed in percent, with standing room calculated on the basis of four persons per square meter of standing space. This means that when capacity utilization levels reach around 40 percent, all the seats are occupied and the carriage gives the subjective impression of being full. Capacity utilization levels of more 50 percent can occur during rush hour, but are not necessarily desirable from the perspective of comfort. By contrast, capacity utilization levels of under 5 percent are a clear indication of oversupply.

More precise considerations are, of course, needed to adjust capacity exactly to individual lines. Here, however, some general statements can be made using the example of the bus network (see also Figure 5).

- In overall terms, capacity utilization in the Berlin bus network shows considerable fluctuation. It averages around 17 percent, with some lines above 30 percent and many below 10 percent.

- Capacity utilization is high when buses serve axes with important feeder 

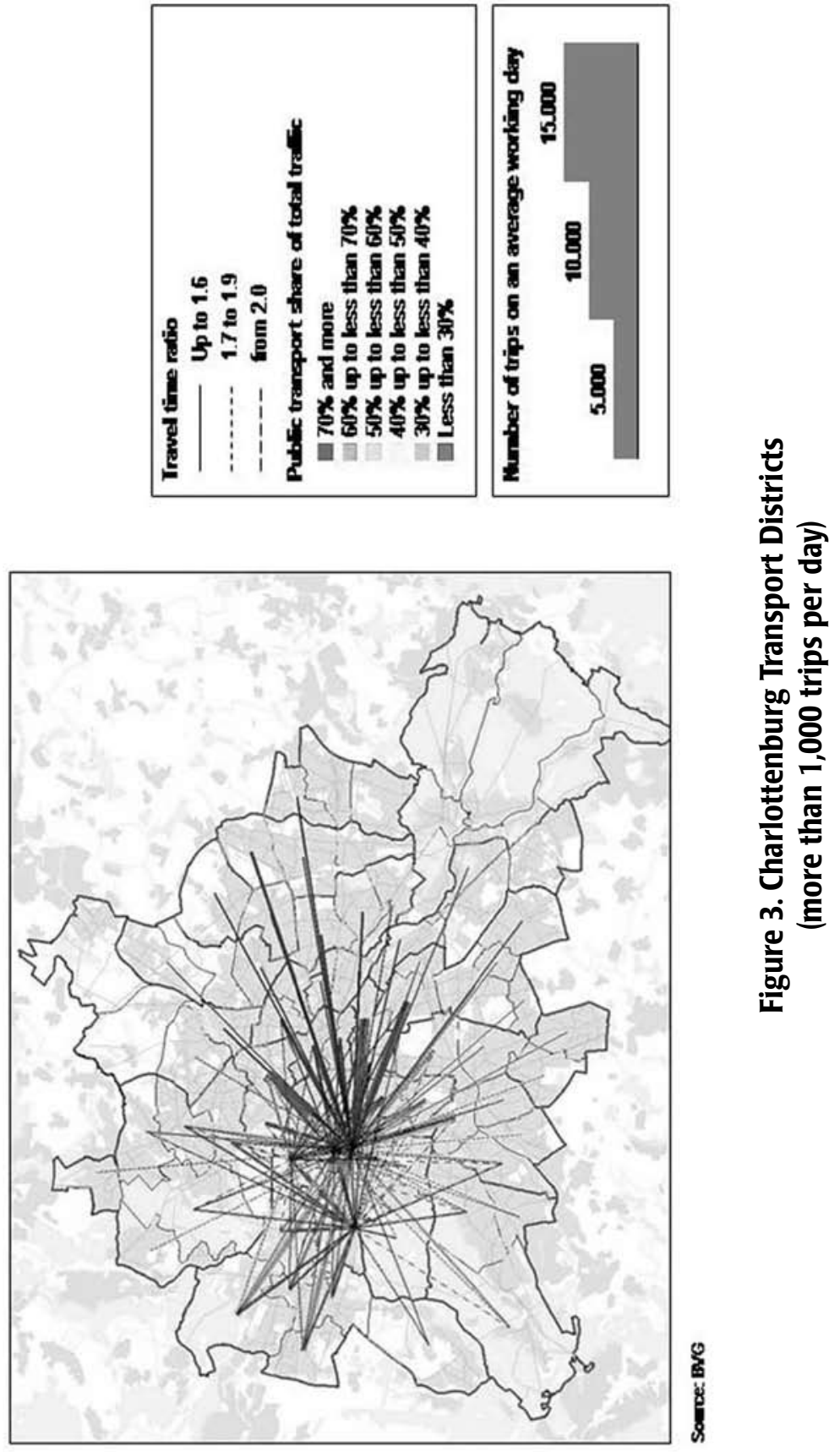
Journal of Public Transportation, Vol. 11, No. 3, 2008

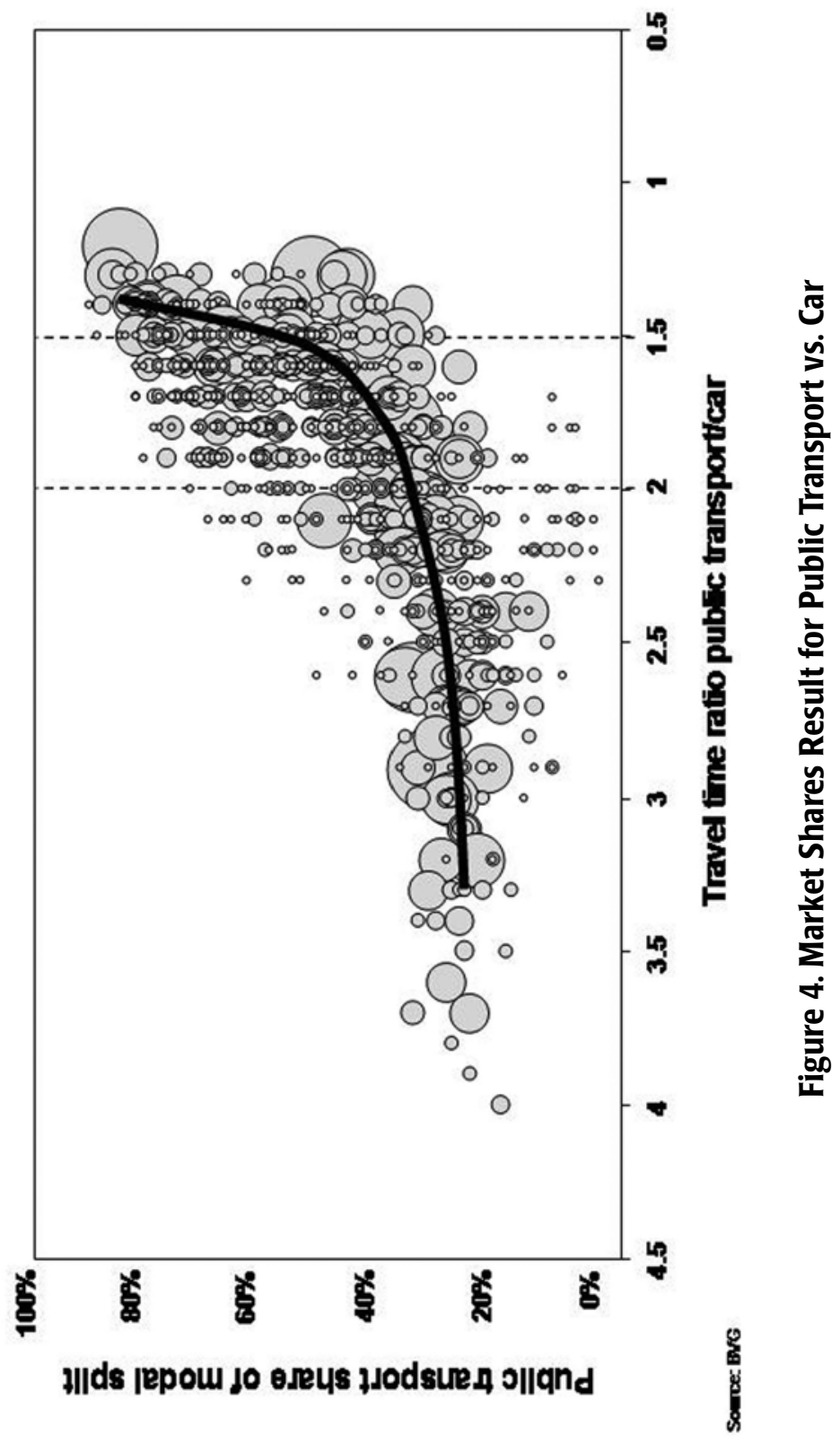



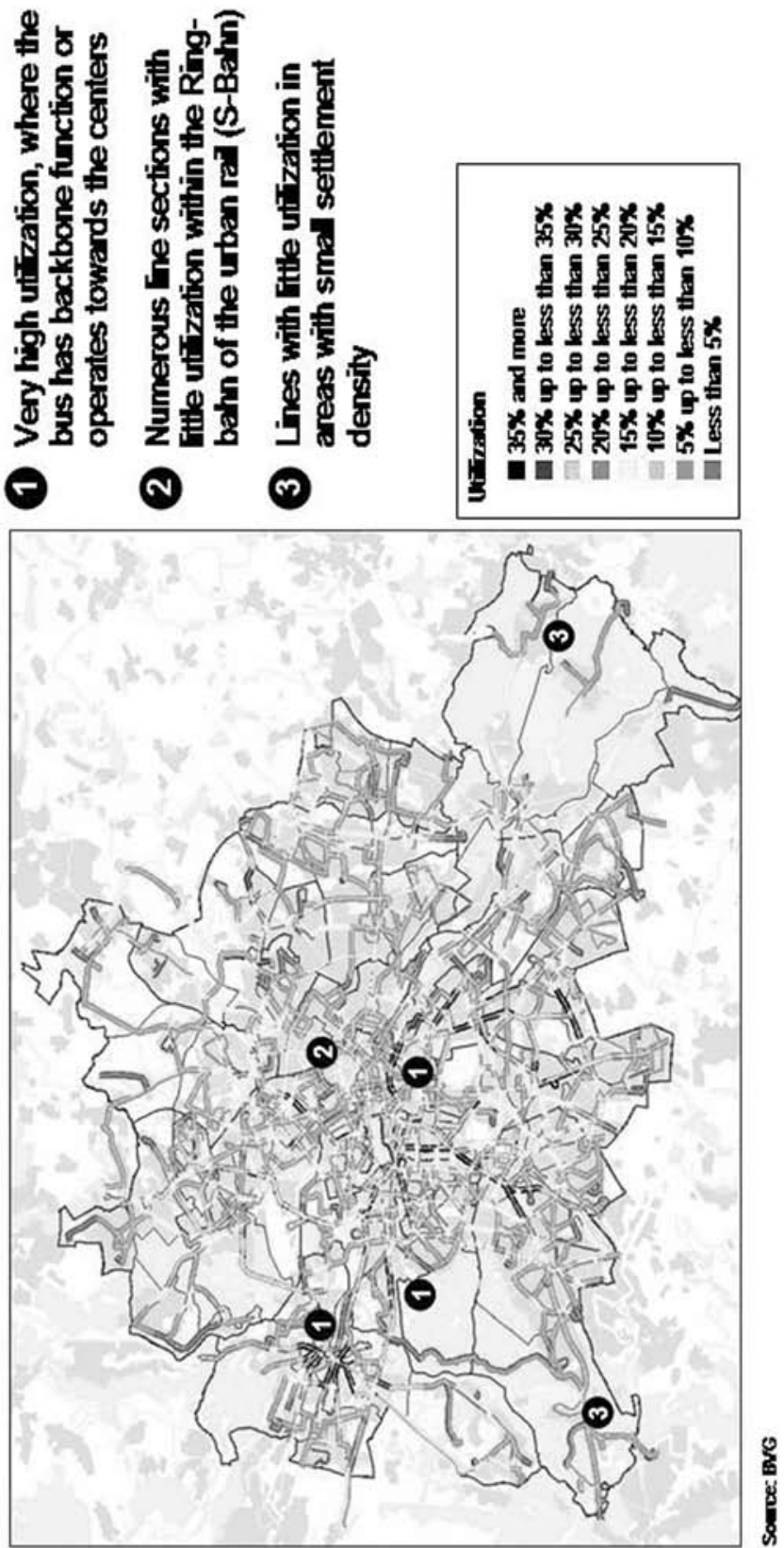

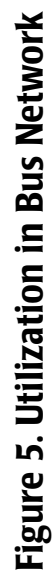


functions for the rapid transit system or major arteries leading to the city center.

- Capacity utilization is low on many supplementary lines inside the Berlin S-Bahn (commuter rail) ring, as well as in the thinly populated outlying areas.

- During rush hour, capacity utilization is high, as expected. The lowest levels are in the early morning hours of the weekends.

\section{Strategic Guidelines}

Results gained from the three different analysis modules-customer demand, competition, and capacity - were used to develop strategic guidelines for network planning, which, in turn, had to be approved both internally and by the city government. The public transportation network was more precisely differentiated, namely into a core network whose services were improved, and a supplementary network that ensures minimum service. The core network of the commuter rail (S-Bahn) and metro (U-Bahn) systems was expanded to include the newly created MetroLines, which are not to be confused with underground metro service but rather consist of buses and trams that serve major traffic axes. MetroLine service was improved such that customers can use these lines as easily as the underground metro lines (i.e., without having to know the timetables). In addition,

- They run throughout the day at short intervals of no more than $10 \mathrm{~min}$ utes.

- Their lines follow major traffic axes in straight lines wherever possible.

- Their links are designed to create a "spider web" similar to that of the commuter rail (S-Bahn) and metro (U-Bahn) system.

The MetroLines represent a spatial expansion of the core network into the outlying districts of the city, and their service also includes tangential connections. Viewed in terms of the usual catchment areas surrounding stations and stops, the new core network consisting of the commuter rail, underground metro, and new MetroLines now covers 87 percent of the residents of Berlin. The commuter rail and underground metro systems alone previously provided only slightly more than 70 percent of the population with premium transportation services.

The supplementary network complies with the directives of the municipal public transportation plan. It continues to ensure that 97 percent of all Berlin residents 
live within 300 meters of a bus stop or within 600 to 1,000 meters of a commuter rail or metro station. In the supplementary network, buses run at intervals of 20 minutes or less and on high-volume lines at intervals of 10 minutes or less. Although some reductions occurred in service here, almost all of these affect peripheral times of day or corridors that are sufficiently covered by other highgrade lines. Only a few lines were entirely discontinued, primarily those that for historical reasons ran parallel to the commuter rail (S-Bahn).

This hierarchical structure of the transportation network, which enables service to be adapted much more closely to actual traffic flow patterns, has made it possible to provide a higher frequency for 37 percent of Berlin's residents, thus improving service. Service remained essentially the same for 58 percent of residents. Only 5 percent of the city's residents were faced with reductions in service, which nevertheless remained at acceptable levels in the eyes of the BVG. As expected, however, when the changes were made, the 5 percent of residents whose service was reduced were considerably more vocal in their reactions than those who benefited from the changes.

\section{Communicating with Customers}

The BVG broke new ground via a number of different channels in its dialog with customers (on-site, Internet, media), which was also designed to help customers understand the reasons for the changes and to neutralize potential criticism at an early stage. Considerable resources were devoted to communications and to strengthening customer loyalty. This was money well spent from today's perspective because this "partial democratization" of the process minimized the risk of planning errors from the start. Customers could inform themselves about the overall project as well as cast votes for individual lines via surveys, on the Internet, and at public events.

Another major element in the dialog with customers consisted of detailed on-site information about the changes in the form of "micromarketing." Sixty different flyers with a total circulation of 2.2 million were printed and distributed to households as well as to information stands, sales offices, and contact points such as shops. It turned out, however, that the expectations raised by this BVG campaign could hardly be met-complaints came from households that did not receive flyers, while the innovative new sales strategy of using small neighborhood shops was ignored by the media. 
The micromarketing campaign was criticized, and justifiably so, for not presenting a sufficiently clear overview of all relevant information. Further criticism was directed at the belated distribution of the timetables, which were not ready until the very day that service changed. This tardiness was due in large part to the fact that the Berlin State Senate stipulated last-minute modifications as part of its approval process. In fact, the BVG did not actually receive its legally-required authorization of the lines until one day before the scheduled change in service.

As far as the customers are concerned, the MetroLines fulfill their promise of simplifying service. Just like the rapid transit system, most customers do not have to study the timetables anymore, or for that matter even look at them. This product also improves orientation within the enormous network of the Berlin urban area. Trains and MetroLines can be used for long distances and to reach major destinations, while "normal" bus and tram lines, ferries, demand-based services, and nighttime lines provide finer meshed coverage and take customers to their precise destinations. The "always there" promise provides not only spatial orientation but also a clear commitment to temporal coverage. The underground metro and MetroLines offer reliable service at nonpeak periods of the day and at night to customers who at these times are generally less familiar with the network and timetables. Nighttime service thus plays a crucial role in upholding the promises made by the new product and service network. It was redesigned in May 2006.

\section{Nighttime Service}

The historical origins of nighttime service are rooted in the need to bring BVG staff to their depots and terminal stations before the start of (daytime) operation, and to take them home again after service stopped at night. Thus, nighttime service was completely different from its daytime counterpart because the two networks had largely different destinations as well as customers. Although the original nighttime network underwent many changes over subsequent decades, it remained very different from daytime service. Yet the demand for nighttime service has now become much more similar to that for the day. Mobility in the night is now marked by more customer groups than before. While nighttime mobility used to be mainly the province of the above-mentioned transport staff as well as shift workers in industry, public utilities, and hospitals, it now includes more customer groups and transport purposes. New types of jobs across a broad range of service sectors as well as the widespread use of these services account for a large part of 
this growth, in addition to expansions in leisure activities and tourism. Mobility for the purpose of shopping has now also extended into the night in Berlin.

The BVG's analysis of nighttime transportation showed only a slightly lower share of the market than for the day. Nighttime traffic has increased, and also shows a greater distribution over most of the central parts of the city. More pronounced traffic flows are evident here than before, with affinities for public transportation.

Based on these conclusions, the new design for the nighttime network included 24-hour service for the MetroLines, 24-hour underground metro service on weekends, and better connections.

When the new timetables went into effect in May 2006, they also included connections to the new Berlin Central Train Station as well as reductions in service for the early hours of the weekends. The MetroLines now run 24 hours a day, 7 days a week (see Figure 6). From 6:00 A.M. until 9:00 P.M. they run at intervals of 10 minutes or less (some at intervals of $3 \frac{1}{3}$ or 5 minutes). From 4:30 to 6:00 A.M. and from 9:00 P.M. to 12:30 A.M., they run at intervals of 10 or 20 minutes. During the nighttime period from 12:30 to 4:30 A.M., the MetroLines run at intervals of 15 or 30 minutes. The underground metro now runs during the night on all lines at 15-minute intervals, although only on Fridays, Saturdays, and before holidays. On weekday nights, the metro trains are replaced by bus lines that serve the same lines and stations. Connections, which had already been coordinated by a computer-supported system, have been increased in number and more clearly publicized, such as in the BVG's public transportation atlas, which is issued at regular intervals.

Around 90 percent of the BVG's customers now note that the same lines they use during the day also run at night. The BVG is therefore anticipating mutual reinforcement between night and day (i.e., greater use of public transportation during the day or night is expected to encourage a higher average number of trips for individual customers).

\section{More Customers Mean Higher Revenues}

All in all, the BVG views its BVG 2005 Plus project as a complete success, and thus it appears that the circle has indeed been squared (see Figure 7 ). This project has enabled the BVG to reduce the annual volume of its operations by 4 million kilometers, with most of these savings taking place in the bus division. This figure is lower than the original target for the project, because objections by residents and 

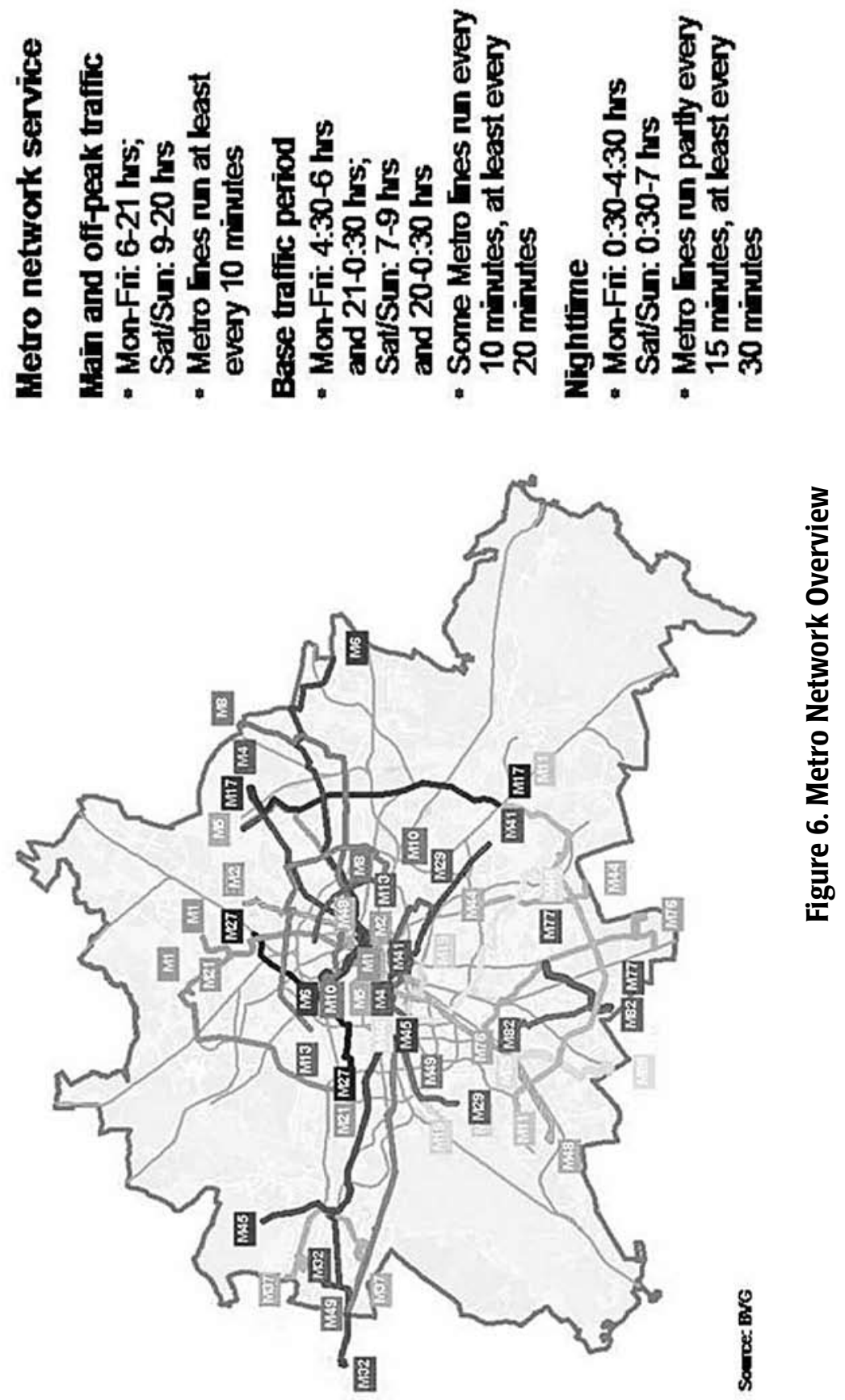
municipal authorities meant that not all the money-saving measures could be implemented. Yet it still enabled a considerable reduction in operations that has resulted in savings of 9.5 million euros per year, as well as an increase of 24 million new trips-or 2 percent of total demand (see Figure 8). Moreover, it has also led to greater revenues for other companies, especially the S-Bahn Berlin $\mathrm{GmbH}$ (commuter rail), which, without changing its own services, has benefited from improved feeder lines and the elimination of parallel bus lines.

Passenger counts carried out over the entire BVG network in 2005 and 2006 to assess the changes in demand show that the anticipated increase in passenger volume has in fact taken place. In terms of development, the MetroLines have proven to be especially attractive. Not only has the number of customers shown a clear increase where service intervals were shortened, but the largely unchanged lines have also gained customers thanks to enhanced marketing of the core network and the product promise of the MetroLines. Ticket revenues have also risen as expected, which indicates that the increased number of rides is due in fact to newly acquired customers as opposed to more intensive use of monthly passes.

These figures as well as several other effects enter into the BVG's annual accounts of revenue and passenger volume. But still other effects, such as fare hikes, counter these positive results by lowering the number of customers. In a study for the year 2005, the BVG performed a detailed investigation of these different effects and determined their quantitative outcomes. With respect to ticket revenues, two negative effects were met by seven positive effects, including optimized service. Regarding passenger volumes, four negative effects (including the fare hikes) faced three positive effects, also including optimized service.

Berlin's public transportation services are now entering a phase that will not feature large-scale changes, during which both current and potential customers can become better acquainted with the newly designed network. The BVG will support this process with the help of targeted product information, advertising, and enhanced sales activities. In view of developments, such as those in Hamburg where the MetroLines continued to attract new customers several years after their introduction, the BVG hopes to enjoy increasing passenger volumes as well as revenues well after the project is concluded. 

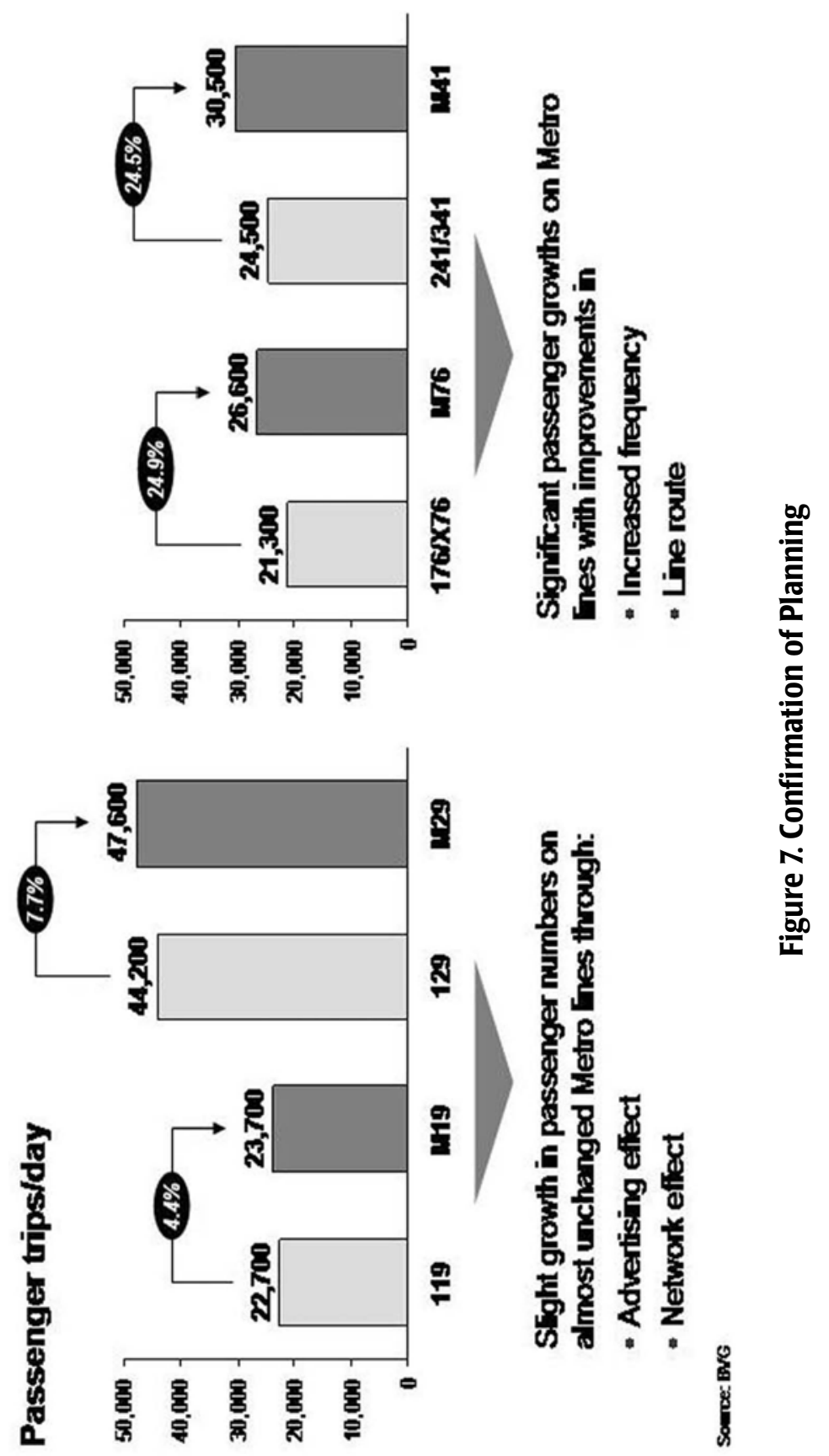


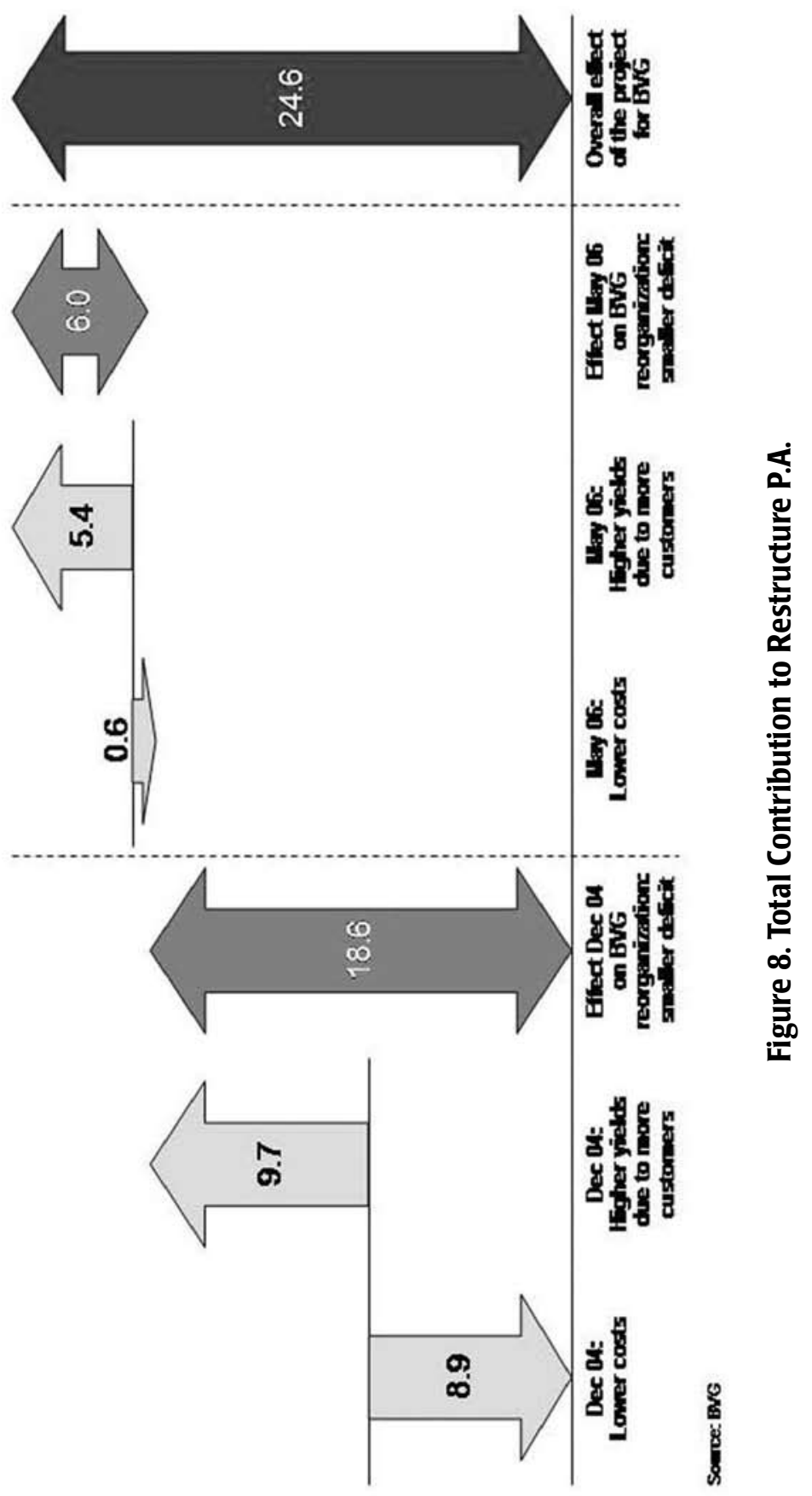




\section{About the Author}

TOM REINHOLD (tom.reinhold@atkearney.com) studied transportation planning and operations from 1989 to 1992 at the Technical University Berlin. He earned his Ph.D. from the Institute for Transport Economics and Transport Policies. As a visiting scholar he studied at the Institute for Transportation Studies at the University of California in Berkeley. From 1996 to 1999, he worked at the research division of the BMW Corporation. In 1999, he joined Roland Berger Strategy Consultants where he became senior project manager in the field of public transportation. From 2003 to 2007, Dr. Reinhold was executive director of the Berliner Verkehrsbetriebe (BVG) with responsibility for the marketing division, which includes corporate planning for the transportation network, fare and ticket structures, marketing communications, and sales. The findings of this article are derived from this period. In November 2007, Dr. Reinhold joined A. T. Kearney as principal, where he is responsible for the railway and public transport business in Central Europe. 